\title{
094 \\ Coordination and information management mechanisms of the tsunami emergency and rehabilitation operations in agriculture, fisheries and forestry sectors in Sri Lanka
}

\author{
W M B S Nissanka \\ Reconstruction and Development Agency (RADA), Colombo 01, Sri Lanka
}

The widespread destruction caused by tsunami on December 26, 2004 brought a heavy toll on livelihoods and natural resources in the three sectors. Numerous international and national organizations assist the affected areas with main aim of restoring shattered livelihoods and for rehabilitation of natural resources for sustainable use by mitigating such disasters in the future.

Several projects were initiated to assess the damages and to restoring to build those back better. However, due to increasing number of emergency and rehabilitation projects in affected areas, there is a problem of coordination and sharing resources. Therefore, this study was focused to assess present status of coordination activities, to share experiences and knowledge for development of sustainable future plans and strategies for coordination and information management in the long run.

The study examined and reviewed the current situation with multi stakeholder participation from government, non government, private sector and community with regard to objectives of the study. Outputs were categorized under; overall status of mechanisms, opportunities for further development and improvement mechanisms best suited for Sri Lanka in line with the "build back better" strategy, and the way forward in terms of information management, exchange and coordination mechanisms for future work.

The study revealed that the need of cross sectoral coordination and information sharing is essential due various reasons such as large volume of information, as to achieve better accuracy and targeting etc., The study proposes to setup divisional/district level mechanism and focal point for coordination and information sharing among Government, donor, private agencies and I/NGOs. There will be similar setup at provincial and national level. The study further proposes certain guidelines such as, to have a focal point in each agency for dissemination of information, making coordination mandatory than voluntary, ethics in data use, giving due regard for Information management process by way of collection of specific data, sharing of data etc., Finally, two models are proposed for coordination and for information sharing among three main sectors.

\section{5 \\ Post-tsunami natural regeneration of coastal vegetation in the Hambantota district in south-eastern Sri Lanka.}

\author{
M S J Perera', C N B Bambaradeniya², P G D R Perera ${ }^{3}$ V A M P K Samarawickrema ${ }^{2}$ and H D D C K \\ Perera $^{2}$ \\ 'Department of Natural Resources, Sabaragamuwa University of Sri Lanka, \\ Sri Lanka. \\ ${ }^{2}$ The World Conservation Union (IUCN), Sri Lanka Country Office, Colombo, \\ Sri Lanka. \\ ${ }^{3}$ The Open University of Sri Lanka, Sri Lanka.
}

A qualitative rapid survey was conducted in 45 plots distributed in the gentle seashore vegetation and sand dunes $(n=13)$, coastal scrublands $(n=19)$, and mangroves $(n=13)$ along the coastline of Hambantota District, affected by the Indian Ocean tsunami. The objective of the survey was to investigate the natural regeneration of coastal vegetation 20 months after the tsunami disturbance.

21 plant species belonging to 19 families were recorded as the prominent plants regenerating in affected mangroves, while 16 species in 15 families and 32 species in 23 families were observed as prominent plants to regenerate in affected areas of the gentle sea-shore vegetation and coastal scrublands respectively.

Proceedings of the International Forestry and Environment Symposium 2006 of the

Department of Forestry and Environmental Science, University of Sri Jayewardenepura. Sri Lanka 